\title{
O ESTADO E O MERCADO: ESTUDO PARA A INTUIÇÃO DE UMA ÉTICA ECONÔMICO-JURÍDICA.
}

\author{
THE STATE AND THE MARKET: A STUDY TO THE INTUITION OF AN \\ ECONOMIC-LEGAL ETHIC.
}

\section{${ }^{1}$ Everton Das Neves Gonçalves \\ ${ }^{2}$ Joana Stelzer}

\section{RESUMO}

$\mathrm{O}$ artigo propõe abordagem sobre a interação entre o Estado de Direito e o mercado segundo a análise econômico-jurídica como instrumental para investigação da fenomenologia social, em especial, quanto aos reflexos produzidos pela ação dos agentes Estatais operadores do Direito na ação dos agentes econômicos em mercado, destacando a eficácia do papel normativo e disciplinador do Estado. Denota a ingerência estatal sobre o mercado, não raras vezes, causando externalidades nefastas para a fluidez das relações de produção. Por outro lado, aponta para o equivoco do Estado minimalista em uma sociedade civil enfraquecida em seu poder civil e econômico, dessa forma, apresenta a possível crítica ao economicismo jurídico. Para tanto, destacam-se as premissas teóricas de doutrinadores defensores da visão econômico-jurídica, como Karl Marx, Rudolph Stammler e os defensores da racionalidade econômico-jurídica própria da Law and Economics (LaE) como Guido Calabresi, Ronald H. Coase e Richard A. Posner. Objetiva apresentar delineamentos a respeito da simbiose entre o Estado e o Mercado denotando, assim, o perfil político-jurídico-economico da sociedade ocidental hodierna. Utiliza a metodologia econômico-jurídica da Análise Econômica do Direito (AED) e intenta esclarecer os efeitos econômico-sociais gerados pelo implemento da ação em mercado social, mesmo, segundo o que se defende como Princípio da Eficiência Econômico-Social (PEES). A investigação implica pesquisa qualitativa, servindo-se do meio bibliográfico e legislação. O método de abordagem utilizado é o dedutivo e, quanto aos fins, trata-se de análise exploratória e explicativa. Conclui pela necessidade do Estado intervir no mercado, com seu poder disciplinar e normativo, alcançando-se o que se propõe como Mínimo Ético Legal (MEL); segundo cultura de produção e consumo responsável, inclusora, ética, desenvolvimentista e apropriada para um novo patamar de mercado conforme ao PEES.

Palavras-chave: Estado e mercado, Política pública judicial em mercado, Análise econômica do direito estatal, Responsabilidade econômico-social

\section{ABSTRACT}

The article considers boarding on the interaction between the State of Law and the market pursuant the juridical and economic analysis as an instrumental to investigate the social

\footnotetext{
${ }^{1}$ Doutor em Derecho Internacional. pela Universidad de Buenos Aires. Argentina. Professor pela Universidade Federal de Santa Catarina, Centro de Ciências Jurídicas -UFSC, Florianopolis, Santa Catarina, Brasil, (Brasil) Email: tutortreinamento@gmail.com

${ }^{2}$ Doutor em Direito pela Universidade Federal de Santa Catarina -UFSC, Florianopolis, Santa Catarina. Professor Adjunto pela Universidade Federal de Santa Catarina -UFSC, Florianopolis, Santa Catarina, (Brasil).
} 
phenomenology, in special, referring to the reflections produced by the public agent's action that operating the Law at the economic agent's action in the market, detaching the effectiveness of the normative and disciplinary State's roll. It denotes the in management of the State on the market, frequently cau

sing ominous externalities for the fluidity of the production relations. The other hand, it points to the mistake of the minimal State in the existence of a weakened civil society in its civil and economic power, in this way, it presents a possible critic to the economic think on the juridical praxis. For in such a way, detaching the theoretical premises of defending thinkers of the juridical and economic vision as Karl Marx, Rudolph Stammler and the defenders of the economic-juridical rationality adequate to the Law and Economics (LaE) as Guido Calabresi, Ronald H. Coase and Richard A. Posner. It objectives to present delineations regarding the symbiosis between the State and the Market pointing in this way the politician-economic-juridical way of the currently occidental society. It uses the economic-legal methodology of the Economic Analysis of Law (EAL) and intends to clarify the generated economic-social effect pursuant the implement of the action in the social market and besides by the defended Social Economic Efficiency Principle (SEEP). The inquiry implies in a qualitative research, serving of the bibliographical way and legislation. The used method of boarding is the deductive and, referring to the finalities, it is an exploratory and explicative analysis. It concludes for the necessity of the State's action on the market, with its power to discipline and normative reaching what is proposed as Legal Ethical Minimum (LEM); pursuant a responsible and ethical culture of production and consumerism capable of inclusion and to reach a new stage in the market conform the SEEP.

Keywords: State and market, Judicial public politics in market, Economic analysis of the state law, Economic-social responsibility

\section{INTRODUÇÃO}

Sempre que se discute a aproximação metodológica das Ciências Jurídicas e Econômicas surgem, no espírito do investigador, questões tão imanentes como a sensação de se estar avançando por "campo minado" pela descrença metodológica e ideológica, pela possível incongruência nos desideratos de ambas as ciências, pelo preconceito quanto às máximas teóricas de ambas as ciências e, enfim, pela aridez de conhecimentos tão técnicos. Enquanto o Direito, em geral, tem perspectiva voltada para o resgate do status quo, a Ciência Econômica intenta, a partir dos estudos de séries estatísticas, prognosticar tendências futuras para a ação social

Dificuldades várias se apresentam para coadunar as percepções econômico-jurídicas; entretanto a simbiose entre as duas Ciências não é inovadora. Exemplificativamente, lembrem-se dos grandes e destacados esforços de José da Silva Lisboa, mais conhecido como Visconde de Cairú que escreveu, em 1804, sua obra capital, Princípios de Economia Política. Liberal, o autor já nos idos de 1808, recebia a Cátedra de Economia Política por ordem Imperial tendo, assim, influenciado sobremaneira o Direito de então, inclusive, tendo solicitado a Dom João VI, a abertura imediata dos portos brasileiros que ocorreu naquele ano. A referida 
Cátedra perdurou sob sua batuta até o ano de 1823 e, em 11 de agosto de 1827, Lei Imperial criava as duas Faculdades de Direito de Olinda e de São Paulo em que já se verificava, na grade curricular do $5^{\circ}$ ano, a Cadeira de Economia Política. Destarte, até hoje, os Cursos de Direito apresentam, em suas grades curriculares, Disciplina de Economia Política, sendo de destacar, no Brasil, esforços mais recentes em Direito Econômico, como os do saudoso Professor Washington Peluso Albino de Souza (2003), em Belo Horizonte; Alberto Venâncio Filho (1968), no Rio de Janeiro; Modesto Carvalhosa (1973), Geraldo Camargo Vidigal (1977), em São Paub e tantos outros expoentes nacionais no Direito Econômico. Da mesma forma, aém das Disciplinas de Economia Política ministradas nos Cursos de Direito, desenvolvem-se atuais estudos próprios do que se conhece como Law and Economics.

$\mathrm{Na}$ prática acadêmica do ensino quanto à simbiose entre o Direito e a Economia, percebem-se, logo, duas grandes Disciplinas, a saber: o Direito Econômico e a Análise Econômica do Direito. Enquanto o primeiro cuida da disciplina jurídica dos fenômenos econômicos da produção, da repartição, da circulação e do consumo da riqueza, o segundo é metodologia de análise do Direito embasada nas máximas da Microeconomia. Assim, para que se iniciem os estudos sobre as possibilidades entre o Direito e a Economia tem de serem vencidos os primeiros obstáculos, dentre os quais, o preconceito acadêmico.

Enquanto os juristas resistem em não aceitar as máximas matemáticas da Ciência Econômica, os economistas ressentem-se da formalidade normativa que entrava o livre mercado. Os primeiros defendem critérios de justiça formal e os segundos a eficiência. Apesar disso, defende-se que a interação entre as duas visões é necessária e benfazeja até porque o homo oeconomicus e o homo juridicus são inseparáveis na existência e, portanto, quando do exercício da tomada de decisão que se almeja, justa e eficiente.

No Estado de Direito democrático, sob a égide da Lei, organizam-se os Poderes. No Brasil, o Texto Magno de 1988 prevê a existência dos Poderes Executivo, Legislativo e Judiciário que devem nortear-se, em sua atuação, pela Legislação. Destarte, na jurisdição brasileira impera a Lei em sua força maior para fins de construção dos objetivos nacionais de respeito aos direitos e garantias individuais e coletivos, ao exercício responsável dos Poderes e, enfim, ao desenvolvimento sócio econômico da Nação com sustentabilidade.

Por outro lado, a Economia tem sua lógica própria com específicas leis (oferta, demanda, elasticidade da demanda, estruturas de mercado, etc.). Portanto não se pode conduzir a Economia a despeito da Teoria econômica sob pena de se impetrar o caos 
econômico-social pelo desmando na tomada de decisão econômico-social que, antes de implementar o bem estar, implicará em retrocesso econômico.

Em que pese o afirmado, a criação da Lei, e sua eventual apreciação peb Poder Judiciário, não se pode ver desconectada da realidade social fática sob pena de esterilidade da norma. Administrar a Economia de dado País com decretos normativos desconectados das Leis Econômicas é perpetrar o caos e a ineficácia normativo-judicial. Não obstante o afirmado, surpreendentemente, os governantes e operadores do Direito assim o fazem Da mesma forma, aplicar a Lei e, eventualmente, julgar, em sociedade, de forma a não levar em conta os reflexos econômico-sociais da tomada de decisão judicial é perpetuar a injustiça.

Resta importante, então, detectar a medida possível para a interação entre o instituído, o Estado com sua normatividade, e o mercado em que os agentes econômicos, também, sujeitos de direito, atuam Defende-se, assim, a interação entre o Estado de Direito e o mercado segundo instrumental de análise econômico-jurídica dos reflexos produzidos pela ação dos agentes Estatais operadores do Direito na ação dos agentes econômicos em mercado. Há que se defender, assim, a eficácia normativa e disciplinadora do Estado conectadas com as estratégias decisórias dos jurisdicionados que, evidentemente, absorverão os custos impostos pela ação Estatal de forma a maximizar seus interesses, mesmo que publicizando, para terceiros, os possíveis prejuízos, externalidades, impostas pelo Estado. Frequentemente, o Estado, através de seus agentes legisladores e julgadores, incorre em ingerência sobre o mercado, não raras vezes, causando externalidades negativas para a fluidez das relações de produção. De outra forma, os agentes econômicos sujeitos às imposições estatais responderão, senão a curto, a médio e longo prazo, de forma a maximizarem suas expectativas e absorverem os custos advindos da tomada de decisão estatal.

Por outro lado, verdadeiro equivoco é a defesa de um Estado minimalista quando observada uma sociedade civil enfraquecida em seu poder decisório e econômico. Não há justiça social e nem econômica em uma sociedade desigual nas oportunidades de seus sujeitos de direito; o que, certamente, justifica a crítica ao economicismo jurídico que perpetua a acumulação de mercado.

A partir do exposto, objetiva-se delinear a simbiose entre o Estado e o mercado denotando-se o perfil político-jurídico-economico da sociedade ocidental hodierna. Tem-se, como problema de estudo, averiguar, em tese, o possível reflexo, na Economia, das decisões normativo-jurídicas. A imposição normativa ou judicial teria influencia na tomada de decisão dos agentes econômicos, sujeitos de direito, em sociedade? Haveria redistribuição do risco em sociedade, em virtude da inexorável tentativa dos jurisdicionados em maximizar suas 
expectativas econômico-sociais em virtude das imposições estatais? Seria possível julgar interpartes sem influenciar a tomada de decisão dos sujeitos de direito em sociedade?

Utilizando-se metodologia econômico-jurídica da Análise Econômica do Direito (AED) se esclarecem os questionamentos acima referidos defendendo-se que a toda ação estatal, corresponde reação dos particulares, inclusive, promovendo efeitos econômico-sociais muito díspares daqueles pretendidos pela Lei ou pelos julgados. Em verdade, os efeitos sociais da tomada de decisão normativo-judicial podem ser totalmente adversos às intenções pretendidas pela mens legis ou pelo decidendum dos julgadores.

Trata-se, a investigação, de pesquisa qualitativa, servindo-se do meio bibliográfico e legislação. O método de abordagem utilizado é o dedutivo e, quanto aos fins, trata-se de análise exploratória e explicativa. In finis, defende-se o implemento da ação em mercado social segundo defendido por Gonçalves e Stelzer (2014) como Princípio da Eficiência Econômico-Social (PEES) . A normatżação e a apreciação judicial da norma não pode ser desconexa da realidade social ou da racionalidade dos jurisdicionados que, incontestavelmente, respondem aos estímulos estatais de forma a maximizar suas expectativas, mesmo que redistribuindo custos e riscos em sociedade e, em última instancia, ocasionando ineficiência social. Conclui pela necessidade do Estado intervir no mercado, com seu poder disciplinar e normativo, alcançando-se o que se entende como Mínimo Ético Legal (MEL); segundo cultura de produção e consumo responsável, inclusora, ética, desenvolvimentista e apropriada para um novo patamar de mercado conforme ao PEES.

\section{DA APROXIMAÇÃO TEÓRICA DO DIREITO À CIÊNCIA ECONÔMICA}

Para que se possa avançar no estudo do Direito a partir de premissas econômicas, necessário se faz verificar as possibilidades de aproximação entre as duas Ciências. Não se pode aceitar axiomas inquestionáveis, mormente, pelo argumento de autoridade e que não se sustentam ao crivo do método científico. Há que se vencer o preconceito acadêmico. Defendese que o Direito não tem hegemonia absoluta sobre a Ciência Econômica e vice-versa; ainda que ambos, sobremaneira, influenciem um no outro. Três premissas teóricas sobre a reflexiva influencia de uma Ciência em outra podem ser indiferentemente adotadas pelo leitor. A um; têm-se os doutrinadores defensores da visão econômico-jurídica segundo o determinismo histórico de Karl Marx (1982, 10) em que a estrutura gera a superestrutura; a dois, seja 
lembrado o posicionamento de Rudolph Stammler (1929, 138), para quem o Direito implica organizar a sociedade para uma ação concatenada em função de determinados fins, enquanto existem duas verdades, a saber, a formal (do mundo do Direito) e a real (mundo fático da Economia) e; a três, destaque-se o pensamento dos defensores da racionalidade econômicojurídica própria da Law and Economics (LaE) como Guido Calabresi (1961), Ronald H. Coase (1960) e Richard A. Posner (1973, 1977, 1992), dentre outros, que reconhecidamente defendem a reflexividade entre os ditames do Direito e da Ciência Econômica. È improdutiva qualquer discussão que vise determinar proeminência de uma Ciência sobre a outra, visto que o importante é vislumbrar que ambas se complementam na apreciação da fenomenologia social. Esse é o necessário posicionamento que deve ser apresentado; mormente, nas salas de aula em que os jovens estudantes, não raras as vezes, empenham-se em discussões estéreis na defesa de bandeiras político-ideológicas que fogem ao cientificismo com que o assunto merece ser tratado.

Ainda, percebendo-se que o Direito busca dado critério de justiça; da mesma forma, a Ciência Econômica se ocupa do dilema da escassez e da necessidade de eficiência no uso dos recursos produtivos. Justiça e eficiência são metades da mesma verdade que se sobrepõem alternadamente ou se complementam ordenadamente, mormente, segundo a visão determinista de KARL MARX (1982, 10); a ação concatenada de RUDOLPH STAMMLER (1929, 138) ou, ainda, a interação simbiótica entre o Direito - verdade formal e o fenômeno econômico - verdade real como defendem os pensadores da LaE.

No sentido de aproximação entre o Direito e a Ciência Econômica ainda pode ser lembrado o pensamento segundo enfoque sociológico de MAX WEBER (1964, 652/653, 1992) esclarecendo que a lógica jurídica puramente profissional e o Direito abstrato e distante do fenômeno social contrariam as expectativas sociais, pois, estas, são orientadas de acordo com o sentido econômico ou prático-utilitário de uma norma jurídica. Destarte; entende-se que, em meio às escolhas políticas próprias dos sistemas econômicos constitucionalmente adotados, é imperativo emergir respectivo Direito que, em qualquer circunstância, deve zelar pelos interesses e prerrogativas tanto dos possuidores como dos despossuídos, dos incluídos e dos socialmente excluídos; sendo, a justiça, o locus para a tomada de decisão pragmática e eficiente, ainda, garantindo para a pluralidade das sociedades presentes e futuras a conservação de suas prerrogativas.

A aproximação entre Direito e Economia pode ser vista, assim, sob o enfoque do Direito Econômico $^{1}$ e das Escolas2 da Análise Econômica do Direito (AED), segundo o enfoque 
tradicional da Escola de Chicago, Law and Economics (LaE) 3, o enfoque Neoinstitucional ou vertente dos Property Rights 4, o enfoque chamado de Eleição Pública, Public Choice5 e, ainda, pelos conhecidos Estudos da Crítica Jurídica (ECJ) 6. Com visão econômico-jurídica própria da LaE, ainda, são destacados autores como: RONALD COASE7, GUIDO CALABRESI8, GUIDO ALPA9 e RICHARD ALLEN POSNER (1977, pp. 15 e 16).

Uma vez vencida a dicotomia Direito \& Ciências Econômicas, resta, então, verificar a possível ou, em verdade, verificável influencia da normatividade erga omines no meio social

1 Ver Gonçalves e Stelzer (2009).

2Andrés Roemer $(1994,4)$ analisa quatro enfoques da disciplina em questão: o tradicional - de Posner, o neoinstitucional, o da public choice e os Estudos da Crítica Jurídica. Consagrou-se a expressão Law and Economics para designaro enfoque tradicional da Escola de Chicago também conhecido como Institucionalista. Ver, também, Gonçalves e Stelzer (2007).

3 Como subsídio bibliográfico ver: COOTER (1988); HIRSCH (1988); POSNER, (1977); SHAVELL (1987) e POLINSKY (1985).

4 A respeito do enfoque neoinstitucional da LaE, podem ser verificadas as obras de MERCURO (1989); FURUBOTN e PEJOVICH (1974); WILLIAMSON (1989).

5 Enriqueça-se a pesquisa consultando FARBER e FRICKLEY (1987); TULLOCK (1965; 1991); MUELLER (1979); DOWNS (1957); BLACK (1958); STIGLER (1971); BUCHANAN (1993).

6 Para apreciação histórica do movimento ECJ ver as obras de SCHELEGAL (1984, pp. 391-411) e SCHWARTZ (1984, pp. 413-455); ALTMAN (1993); bem como, do brasileiro MANGABEIRA (1983).

7 Ronald Coase, economista, foi professor de Richard A. Posner, no final dos anos cinquenta. Na Virginia University, escreveu divorciando-se das teorias de A. C. Pigou, defendendo a necessária e eficiente reparação do custo social - externalidades, não segundo quem o causou, de forma apriorística, porém, segundo quem melhores -eficientes - condições tivesse para arcar com o ônus da internalização, no cálculo econométrico, principalmente, das chamadas externalidades negativas. Defendeu, como principal axioma, que quando os custos de trans ação estão zerados, é indiferente a adjudicação de direitos. Para maiores informações, ler COASE (1960).

8 Guido Calabresi foi professor de Yale e trabalhou a questão da distribuição dos riscos através do Torts Law, reconhecendo a reciprocidade de interesses quando da solução do problema das externalidades negativas geradas pela ação danosa que deveriam ser adjudicadas, pelo direito de indenização, segundo critérios de eficiência. Ver sua principal contribuição in CALABRESI (1961, p. 499 e 1984).

9 Guido Alpa escreveu na Itália, destacando-se: ALPA (1982).

ou dos julgados concretos interpartes, para além das partes envolvidas. De fato, to da a ação normativa ou judicial acaba por influir, indelevelmente sobre a distribuição ou redistribuição da riqueza individual e socialmente apropriada. É o que se passa a verificar.

\section{DA INFLUENCIA DAS NORMAS E DOS JULGADOS NO MEIO ECONÔMICO- SOCIAL}

Toda a tomada de decisão, inclusive, normativa ou jurídica, implica um tradeoff, ou seja, em um custo de oportunidade, que, por sua vez, vem a ser a perda verificável segundo o abandono de dada opção de decisão em função do ganho adjudicado pelo agente com a decisão tomada ou adotada. Nessa perspectiva, toda a tomada de decisão representa um ganho 
e uma respectiva perda. Assim sendo, todo o direito tem seu custo. È impossível, então normatizar ou decidir sem distribuir ou redistribuir riqueza (recursos escassos, em sociedade).

Para o Direito, a ideia de custo de oportunidade representa a tomada de decisão jurídico-normativa dos agentes estatais, optando por garantir determinado direito ao cidadão em detrimento de outro ou outros. A escolha entre uma ou outra polifica normativa ou judicial consome recursos e redistribui riqueza entre os agentes envolvidos, por exemplo, em um processo judicial; ou, ainda, sinaliza, para a sociedade em geral, como o Estado entende devam ser adjudicados os escassos recursos entre os sujeitos de Direito. Isso é aceitável, desde que os agentes estatais tenham pleno conhecimento dos reflexos econômicos de suas ações em sociedade, sob pena de se verificarem efeitos adversos á intenção estatal por parte da reação dos agentes (sujeitos de direito) em sociedade, que, inevitavelmente, procurarão maximizar suas expectativas a despeito da vontade estatal

Mal formulada a políica pública normativa ou judicial e a tomada de decisão do agente público, sinaliza-se resultado ineficiente para a sociedade civil pelo inevitável desperdício de riqueza.

O Estado, com todas as suas instituições normativo-jurídico-decisionais, influencia e sinaliza, para a sociedade; inclusive, para além das partes envolvidas em um processo, a forma como a riqueza deve ser distribuída ou redistribuída entre os sujeitos de direito.

Oliver Williamson (2011, 21 e ss.), como neoinstitucionalista, defende a influencia das instituições (Estado e Direito) no mercado, inclusive originando as fallhas (ou externalidades negativas) de mercado pelo desvio do ótimo uso dos recursos escassos. Aliás, essa é a crítica neoliberal ao instituído. O Estado, por não ter adequados parâmetros para avaliar os interesses dos agentes acaba por interferir, ineficientemente, na distribuição da riqueza individual e social.

Em uma visão liberal eficiência implica na otimização do uso dos escassos recursos, seja segundo Pareto $(1939,1984)$ ou conforme Kaldor e Hicks (1939) de forma a serem obtidos os maiores benefícios em detrimento dos menores custos. Em que pese a visão liberal, a tônica intervencionista de Estado tornou-se presente desde o inicio do Século XX, já no Constitucionalismo Mexicano, de 1917; na Declaração do Povo Trabalhador e Explorado da República Socialista Soviética, de 1917; na República de Weimar, de 1919; e no intervencionismo estatal da planificação, como visto no New Deal de Franklin Delano Rosevelt, de 1933 a 1937, dentre outros exemplos.

Quanto ao repensar do intervencionismo estatal, diferentemente de Arthur Cecil Pigou (1932), Ronald Coase (1960) releu a ação intervencionista de Estado nas relações privadas 
defendendo o que Joseph Stigler $(1971,1987)$ viria a denominar Teorema de Coase pelo qual se tem que, quando os custos de transação são zero ou próximos de zero, tanto faz para quem o Direito adjudicará a prerrogativa normativa ou jurídica, pois, nesse caso, certamente, as partes envolvidas haverão de chegar a um eficiente acordo em função do exercício de sua liberdade para tomada de decisão sobre interesses reflexivos. Por outro lado, quando os custos de transação são altos; é muito adequado que o Estado determine, via Direito, a devida adjudicação dos interesses. O Teorema de Coase tem uma grande virtude específica; qual seja, a reciprocidade de interesses entre os agentes em sociedade. Portanto, toda vez que se cria uma nova lei ou que um julgador sentencia, automaticamente se está a redistribuir riqueza. Ponto crucial, então, é verificar se este processo distributivo ou redistribut ivo é justo e eficiente. Assim, toda a decisão eficiente será justa, porém, nem toda a decisão justa será eficiente.

Para clarificar e, a tífulo de exemplificação, intente-se analisar, ainda que hipoteticamente $^{10}$, os resultados sociais advindos pela adoção de determinadas políicas normativas ou judiciais demonstrando a influencia das normas e dos julgados no meio econômico-social.

Pense-se, então, a despeito do que, normalmente, é ensinado nos Cursos de Direito brasileiros, quando se faz indiscutível apologia do Código de Defesa do Consumidor (CDC) e das normas ambientalistas; no que concerne às relações consumeristas e ao Direito Ambiental,

\footnotetext{
10 Evidentemente, que qualquer das hipótese a seguir são plenamente demonstráveis uma vez verificadas, em dado Tribunal ou no Conselho Nacional de Justiça Brasileiro, as estatísticas, hoje, mais facilmente disponíveis. Deixa-se de fazê-lo por três motivos a saber: a um, em virtude do inadequado espaço do presente paper para tal demonstração; a dois, em virtude de não se querer ater a um único Tribunal ou a única questão de exemplificativa de Direito e, a três, pelo fato de que não interessa, para fins acadêmicos, demonstrar o popsicionamento de determinado Tribunal brasileiro a respeito de dado caso concreto, ainda que isso fosse plenamente exequível.
}

em visão econômico-jurídica, há efetiva proteção do consumidor e do meio ambiente em função da normatividade? Em outras pahuras, a Legislação do Consumidor (CDC - Lei 8078/90) realmente protege o consumidor? Da mesma forma, a Legislação de Concorrência (Lei 12.529/2011) incentiva ou obstaculiza o mercado? E quanto à Legislação ambiental, em geral protege o meio ambiente?

Aparentemente fáceis de serem respondidas, tais questões impõem análise mais profunda na medida em que se verifiquem os reais interesses que podem ser prejudicados em detrimento da proteção inquestionável de outros vabres que, em verdade, encontram-se em situação de reciprocidade uns com os outros. 
A visão do jurista-economista entende tratarem-se de recíprocos direitos a serem adjudicados em sociedade (dos consumidores, dos defensores do meio ambiente e dos empresários); isto é, a serem consagrados ou definidos pelo Direito, no caso brasileiro, codificado (Civil Law). A questão crucial, entretanto, segundo o Teorema de Ronald Coase, está em se verificar qual interesse deve prevalecer em detrimento de outro segundo cálcub econométrico de tomada de decisão jurídico-normativo-judicial, sob pena de ineficácia da norma ou do julgado. Assim não se defenderia, ab initio, nem por garantir, exclusivamente, o meio ambiente e nem por proteger, inquestionavelmente, o consumidor; como também, não se defenderia a voracidade do empresário. Todos esses direitos e prerrogativas são plenamente dignos e defensáveis e a prevalência de uns sobre os outros implica inevitáveis trade offs.

Como, então, normatizar, no Legislativo, ou decidir, no Judiciário quanto à adjudicação dos recíprocos interesses que estão em discussão? Eis o presente desafio.

Exemplificativamente, o que ocorrerá se forem inseridos artigos, no CDC, extremamente protecionistas do consumidor?

Em uma visão apriorística, entender-se-ia ter sido, o consumidor, efetivamente protegido da voracidade empresarial. Entretanto, sabe-se que para toda ação, existe uma reação, nesse caso, do empresariado. Se o custo da proteção exigido pela norma for de tal monta que inviabilize a produção, certamente, o empresário abandonará a atividade, mormente, se favorável a mobilidade dos fatores de produção. Por consequência óbvia, ao invés de proteger, na verdade, a Lei desfavoreceu o consumidor, pois, na Economia; os agentes econômicos da produção reagirão de forma adversa ao comando legal CDC. Não que os ofertantes possam se comportar contrariamente ao CDC (afinal todos são iguais perante a Lei e ninguém pode alegar o desconhecimento da mesma e descumpri-la); mas, simplesmente, deixarão de produzir ou ofertar determinados produtos em virtude do excessivo aumento de custos para manter a oferta segundo as exigências do CDC. Por consequência se tem o desabastecimento e um enorme prejuízo ao consumidor.

Para além do discurso tradicional das Escolas de Direito e de forma inovadora, deve-se perceber que se não está a defender nem o niilismo normativo e nem a voracidade empresarial ou, ainda, defende-se tanto o consumidor quanto o produtor como partes envolvidas em processo decisório plenamente recíproco e justificável segundo necessidade inquestionável de adjudicação de dado interesse, relevando-se, no entanto, que se tenha consciência (quando da tomada de decisão, por exemplo, na barra dos Tribunais) de quanto de dado bem se está a perder ou ganhar para defender outro bem Essa decisão não pode ser meramente volitiva ou 
políica. Tem de ser técnica. Deve-se sopesar, no cálculo econométrico, o quanto que se ganha em detrimento do que se perde em adjudicando dada políica normativa ou judicial.

Ainda quanto ao Direito Ambiental Se, é justo proteger e defender o meio ambiente (floresta e povos indígenas que, teoricamente, possam ter sido prejudicados pela decisão de instalação de uma hidroelétrica); por outro hdo, assim o fazendo, tem-se que assumir a inexorável crise energética que poderá advir da falta de investimentos em energia para dado País. Em verdade, são, portanto, plenamente dignos e justificáveis ambos os interesses (meio ambiente protegido e a construção da hidrelétrica capaz de gerar energia para o desenvolvimento do dito País). Não se defende, a priori, nem um e nem outro interesse, mas se defende, sim, que a decisão por dada política implica um trade off que deve ser mensurado sendo otimizada a tomada de decisão que, consciente, represente a otimização da riqueza escassa.

Outra questão, embrando, que toda a tomada de decisão jurídico-normativa causará reflexos para a sociedade (custos de transação e externalidades) pode ser elucidada a partir do hipotético exemplo de efeitos econômicos advindos do posicio namento de dado Tribunal (Y). Imagine-se que no Estado (X), o Tribunal de Justiça (Y) tem por consenso que as questões revisionais de aluguel judicializadas por locatários sexagenários contra seus locadores, relacionadas à revisão dos valores pagos a título de aluguel de imóveis devem ser, invariavelmente, decididas a favor dos idosos para que tenham dilatados os seus prazos de pagamento das parcelas em que o débito de aluguéis é, judicialmente, dividido.

Tal decisão, em primeiro momento, é interessante e humana; respeitados os cabelos brancos daqueles idosos que, especificamente, respondem por inadimplência perante seus bcadores ou impetram ações revisionais.

Em que pese a humanidade da tomada de decisão judicial favorecendo o sexagenário, deve ser lembrada a máxima de que a toda a ação, em mercado, corresponde respectiva reação. Nesse caso específico; a partir da tomada de decisão judicial pelo Tribunal (Y), benéfica aos locatários sexagenários, o mercado imobiliário no Estado $(\mathrm{X})$, tendo seus custos de transação majorados pela decisão judicial certamente acirrará as exigências para futuras transações imobiliárias envolvendo sexagenários. Assim, o efeito imediato da decisão do Tribunal (Y) tomada interpartes; em sociedade, será a adoção de contratos mais exigentes para novos aluguéis solicitados pelos sexagenários, exigência de maior número de fiadores, aumento do preço dos aluguéis, etc. Após conhecimento da posição do Tribunal (Y), os locadores passarão, portanto, a adotarem patamares superiores de negociação, aumentando 
sensivelmente as exigências de garantias para novos alugueis e/ou, mesmo, desistirão de alugar seus imóveis para os idosos.

Portanto, a decisão judicial, em verdade, veio a prejudicar o mercado de aluguéis no Estado (X) para os sexagenários que, passarão, definitivamente, a não ter mais condições de alugar imóveis por conta da intervenção extremamente negativa do Estado (X) na Economia, via Poder Judiciário.

Ainda mais um exemplo da inquestionável influencia da normatividade no mercado pode ser vista a partir da criação de uma simples Resolução do Conselho Nacional de Transito (CONTRAN), número 42, de 21/05/1998, que tornou obrigatório o porte do Kit de Primeiros Socorros. Tal medida criou uma indústria de Kits da noite para o dia, no Brasil.

Os exemplos referidos fazem urgir a necessidade de ser repensado o Direito, seja enquanto normatividade, seja enquanto posicionamento judicial, de forma a sopesar sua influencia na sociedade civil sob pena de esterilidade da norma ou dos julgados ou, pior, de ingerência sobre a Economia propiciando custos de transação e externalidades inaceitáveis para os agentes econômicos sujeitos de direito.

\section{DA ÉTICA ECONÔMICO- JURÍDICA}

Ante o exposto, não se está a defender os extremos de uma legislação permissiva ou da inação do Estado enquanto Poder Judiciário; nem tampouco se pode fazer apologia da intransigência estatal que desconhece a capacidade de adaptação dos agentes em mercado transferindo custos normativos e judiciais para as categorias populares mais desfavorecidas (como, por exemplo, os consumidores)

Pugna-se, sim, pelo Direito e pela tomada de decisão judicial capaz de mensurar e de assumir as consequências da opção normativa ou judicial ponderando-se os custos de oportunidade entre dadas opções e seus reflexos em sociedade. Não se pode justificar o ganho privado que desconhece o alto custo social imposto; por outro hdo, não se pode onerar, via norma ou decisão judicial, as relações de produção que devem fluir sim, mas com inclusão social É o que se defende; ética nas relações de mercado sopesadas pela ação disciplinadora e incentivadora do Estado. Portanto não se pugna nem pelo niilismo estatal e nem pela ditadura de um Estado totalitário. Entende-se adequado, o Estado, para dirimir as desigualdades sociais e implementar as condições necessárias para a realização existencial de todos os jurisdicionados presentes e futuros (considerada a questão intergeracional). O Estado, e m última análise 
forma-se pela ação de todos os homens, cidadãos capazes de direitos e cônscios de seus deveres, ainda, competindo-lhe assegurar o desenvolvimento de todos e a correção das distorções seja de indivíduos não adaptados à vida em sociedade, seja pela perpetuação das externalidades negativas em função do egoísmo ainda característico no atual estado de evolução humana. Há que se implementar uma ética de alteridade a partir do desenvolvimento individual e social segundo estudo filosófico, científico e cultural mormente, destacando-se a compreensão da arte de viver e a superação das dores e misérias existenciais pela sublimação própria do desenvolvimento intelectual e emocional $\mathrm{O}$ estudo; seja em qual for a área abordada, inevitavelmente, leva à compreensão e ao conhecimento. A compreensão leva ao outro (alteridade) e à aceitação, de forma que, alcançadas ambas as virtudes, por fim ou consequência, verifica-se a utilização do conhecimento com amor: sabedoria.

Esta, pois, é uma grande meta a ser socialmente atingida; a alteridade, com o despertar da consciência para a arte de contemplação do belo, qual seja, a felicidade.

A sociedade somente poderá se desenvolver, em verdadeira harmonia de interesses, quando a vontade geral manifesta, em cada indivíduo, implicar um ato puro do entendimento que raciocina no silêncio das paixões.

Portanto, a ética econômico-jurídica implica racionalizar o uso da riqueza social, individualmente apropriada, desconsiderando-se o egoísmo irracional, a violência passional, o egocentrismo que não percebe o outro, o Direito que não é justo, a política que não liberta e a Economia que não iguala as oportunidades.

Particularmente, defende-se o Princípio da Eficiência Econômico Social (PEES) (GONÇALVES E STELZER, 2014) como forma de desenvolvimento com inclusão social, conciliando-se os ditames da justiça normativa com a eficiência econômica em busca do uso racional e inclusor da riqueza para as presentes e futuras gerações. O Direito normatizado ou aplicado na barra dos Tribunais não pode restar desconectado das necessidades do pais e de seu povo sob pena de esterilidade; assim como, não pode ser intransigente e determinista a ponto de pecar pela inação de quem não quer mudanças. Os interesses, em sociedade, são recíprocos já que os cidadãos vivem ombreados pelos seus semelhantes e, assim sendo, compete, aos tomadores de decisão normativo-judicial implementar ação benfazeja capaz de conciliar interesses dentro das possibilidades de coexistência pacífica, relevando-se que a cada ação corresponde respectiva reação em mercado que não se admite seja revanchista e desconectada com a realidade do outro. 
Através da apreciação econômico-jurídica própria de uma visão do Direito perpassada pela Ciência Econômica percebe-se que, assim como a contraposição das curvas de Demanda e de Oferta demonstram a reciprocidade de direitos em mercado, ainda fazendo perceber o ótimo ponto de equilibrio econômico no qual se tem derradeira transação em mercado; autor e réu ou agentes estatais e jurisdicionados se encontram no seio do Estado, enquanto sujeitos da arquitetura maior do progresso moral econômico e social.

Há que se perseverar em um Mínimo Ético Legal (MEL) (GONÇALVES E STELZER, 2014) que, dirimindo eficientemente os conflitos de recíprocos interesses, seja capaz de propiciar a inclusão dos desfavorecidos. Objetiva-se, então, a assunção do PEES, como opção de políica jurídica, próprio tanto para a elaboração quanto para aplicação da norma como para sua possível análise judicial O PEES implica otimizar o uso dos recursos escassos sem descuidar, quando da tomada de decisão econômico-político-jurídica, no cálculo econométrico, das variáveis econômico-sociais próprias do MEL caracterizador da inclusão social da preocupação com as consequências intergeracionais, da sustentabilidade, do desenvolvimento no seu mais amplo e promissor sentido, da relevância do homem enquanto motivador e primeira razão para a ação benfazeja em sociedade e acima de tudo, como critério que pondera os tradeoffs das escolhas que não podem perpetuar ganhos privados em detrimento de altos custos sociais.

\section{CONCLUSÕES}

Entendendo que a fenomenologia social deve ser analisada segundo ampla visão acadêmica; atentou-se para a sua análise segundo viés econômico-jurídico. O Direito, visto de forma multi e interdisciplinar pela Ciência Econômica, vislumbra efetividade e eficácia; especialmente, se relevadas, no cálculo econométrico próprio da eficiente tomada de decisão normativo-jurídica, variáveis inafastáveis para a necessária inclusão social e atendimento dos anseios dos jurisdicio nados.

Este artigo propôs tratar sobre a interação entre o Estado de Direito, enquanto normatizador e disciplinador das relações econômico-sociais e o mercado segundo a análise econômico-jurídica, demonstrando, em especial os reflexos produzidos pela ação dos agentes Estatais operadores do Direito na tomada de decisão dos agentes econômicos em mercado.

Através de exemplos elucidativos, intentou-se demonstrar a ingerência estatal sobre o mercado causando externalidades nefastas para a fluidez das relações de produção. Da mesma 
forma, entendeu-se equivocada a defesa do Estado minimalista em uma sociedade civil enfraquecida em seu poder civil e econômico. Destacaram-se as premissas teóricas de doutrinadores defensores da visão econômico-jurídica, como Karl Marx (1982), Rudoph Stammler (1929) e os defensores da racionalidade econômico-jurídica própria da LaE como Ronald H. Coase (1960) e Richard A. Posner (1977, 1992). Apresentaram-se delineamentos a respeito da simbiose entre o Estado e o Mercado denotando, assim, o perfil político-jurídicoeconomico da sociedade ocidental hodierna.

Detectou-se que, invariavelmente, o Direito influencia a Economia e vice-versa, sendo improdutivo defender a proeminência de um sobre o outro; como, também, inadequado é deixar de perceber que, sendo, os interesses, recíprocos em sociedade, não se pode deixar de sopesar, no cálculo econométrico para a tomada de decisão, os reflexos interpartes e extrapartes advindos das escolhas que, por sua vez, sempre representarão um trade off entre as possibilidades fáticas. Defendeu-se, por fim, uma ética econômico-jurídica própria do que se entende por Teoria do Princípio da Eficiência Econômico-Social (PEES) segundo o Mínimo Ético Legal (MEL).Tais categorias teóricas representam distintas possibilidades de interação econômico-jurídica inovadora e socialmente inclusora; progressista e capacitada para a realização dos direitos individuais e sociais de forma eficaz e eficiente; permitindo racionalidade e humanização para a norma positivada, sem perder-se de vista os dilemas da vida, especialmente, humana, em meio aos contextos econômicos, políticos e jurídicos.

Concluiu-se, finalmente, pela necessidade do Estado intervir no mercado, com seu poder disciplinar e normativo, alcançando-se o que se propõe como Mínimo Ético Legal (MEL); segundo cultura de produção e consumo responsável, inclusora, ética, desenvolvimentista e apropriada para um novo patamar de mercado social conforme ao PEES.

\section{REFERÊNCIAS}

ALPA, Guido et al. Interpretazione Giuridica e Analisi Economica. Milano: Giuffrè. 1982.

ALTMAN, Andrew. Critical Legal Studies: a liberal critique. New Jersey: Princeton University Press. 1993.

BLACK, Duncan. The Theory of Committees and Elections. Cambridge University Press, 1958. 
BRASIL, Constituição (1988), Constituição da República Federativa do Brasil. 34. ed. São Paulo: Saraiva. 2015.

BRASIL, Lei 8.078/90, de 11/09/1990 - Dispõe sobre a proteção do consumidor e dá outras providências.

BRASIL, Resolução/CONTRAN 42, de 21/05/1998 - torna obrigatório o porte do Kit de Primeiros Socorros.

BRASIL, Lei 12.529/11, de 30/11/2011 - Estrutura o Sistema Brasileiro de Defesa da Concorrência; dispõe sobre a prevenção e repressão às infrações contra a ordem econômica; altera a Lei no 8.137 , de 27 de dezembro de 1990, o Decreto-Lei n⿳⺈ 3.689, de 3 de outubro de 1941 - Código de Processo Penal, e a Lei ñ 7.347, de 24 de julho de 1985; revoga dispositivos da Lei no 8.884, de 11 de junho de 1994, e a Lei no 9.781, de 19 de janeiro de 1999; e dá outras providências.

BUCHANAN. James M. Custo e Escolha Uma indagação em Teoria Econômica. Tradução de Luiz Antonio Pedroso Rafael. São Paulo: Inconfidentes, 1993.

CALABRESI, Guido. Some Thoughts on Risk Distribution and the law of Torts. 70 Yale L. J. 499,1961 .

CARVALHOSA, Modesto Souza Barros. Direito Econômico. São Paulo: RT. 1973.

COASE, Ronald H. The Problem of Social Cost. 3 J. Law \& Econ. 1, 1960.

COOTER, Robert e ULEN, Thomas. Law and Economics. Harper Collins Publishers, 1988.

DOWNS, Anthony. An Economic Theory of Democracy. Harper and Row, 1957.

FARBER, Daniel A. e FRICKLEY Philip P. The Jurisprudence of Public Choice. Texas Law Review. V. 65, n 5, abr. 1987. 
FURUBOTN, Eirik e PEJOVICH. Svetozar. Introduction: The New Property Rights Literature in The Economics of Property Rights, Ballinger, 1974.

GONÇALVES, Everton das Neves e STELZER, Joana. The Law and the Economic Science: the interdisciplinary possibility at the contemporary Law's General Theory. In Anais da XI Conferência Anual da ALACDE. Brasilia, DF. Berkeley Program in Law \& Economics, Latin American and Caribbean Law and Economics Association (ALACDE) University of California, Berkeley. 2007. Paper 050207-01. pp. 01-18. Disponível em http://repositories.cdlib.org/bple/alacde/050207-01, Acesso em 14/08/2015.

; ___ O Direito Econômico: Extraordinário Instrumento de Desenvolvimento. In Anais do XVIII Encontro Preparatório para o Congresso Nacional do Conselho Nacional de Pós-Graduação em Direito - CONPEDI. Maringá, PR. Florianópolis, SC: Fundação Boiteux, 2009. V. 5. P. 2727-2761. ISBN 978-85-7840-023-1. Disponível em http://conpedi.org.br/manaus/arquivos/anais/maringa/Maringa_integra.pdf Acesso em 14/08/2015.

; __ Principle of Social and Economic Efficiency (PSEE) at the Brazilians Law: the normative and judicial decision taking. In Sequencia: Estudos Jurídicos e Políticos, (S. I.), v. 35, n. 68, pp. 261-290, Jun. 2014. ISSN 2177-7055. Disponível em: https://periodicos.ufsc.br/index.php/sequencia/article/view/21777055.2013v35n68p261/26955. Acesso em: 14/08/2015. Doi: http://dx.doi org/10.5007/2177$\underline{7055.2013 \mathrm{v} 35 \mathrm{n} 68 \mathrm{p} 261}$

HIRSCH, Werner Z. Law and Economics. An Introductory Analysis. 2 ed. San Diego, CA: Academic Press Inc., 1988.

HICKS. The Foundations of Welfare Economics. 49 Econ. J. 696. 1939.

KALDOR-HICKS, Welfare Propositions of Economics and Interpersonal Comparisons of Utility, Economic Journal, v. 49, n. 549, 1939.

LISBOA, José da Silva; Princípios de Economia Política. 1804. 
MANGABEIRA, Roberto Unger. The Critical Legal Studies Movement. Harvard: Harvard University Press. 1983.

MARX, Karl Para a crítica da economia política: Salário, preço e lucro; O rendimento e suas fontes: a economia vulgar; Coleção Os Economistas. Introdução de Jacob Gorender. Tradução de Edgar Malagodi et al. São Paulo: Abril Cultural, 1982.

MERCURO, Nicholas. Law and Economics. Boston: Kluwer Academic Publishers. 1989.

MUELLER, Dennis C. Public Choice. Cambridge University Press, 1979.

PARETO, Vilfredo. Manual de Economia Política. Trad. João Guilherme Vargas Neto. Coleção Os Economistas. São Paub: Abril Cultural, 1984.

PEJOVICH, Svetozar. The Economics of Property Rights: Towards a Theory of Comparative Systems. Boston: Kluwer Academic Publishers. 1990.

PIGOU, A.C. The Economics of Welfare. 4 ed. 1932.

. La Economía del Bienestar. Trad. de F. Sanchez Ramos e Manuel de Torres. Madrid: Aguillar, 1946.

POLINSKY. A. Mitchell. Introducción al Análisis Económico del Derecho. Barcelona: Ariel Derecho, 1985.

POSNER, Richard. Allen. Economic Analysis of Law. 4 ed. Boston: Little Brown, (1973, 1992).

ROEMER, Andrés. Introducción al Análisis Económico del Derecho. Trad. José Luis Pérez Hernández. México: Fondo de Cultura Económica, 1994.

SCHELEGAL, John H. Notes Toward an Intimate, Opinionated and Affectionate History of The Conference on Critical Legal Studies. Stanford Law Review. v. 36. $n^{\circ} 1$ e 2. Jan de 1984. 
SCHWARTZ, Louiz B. With Gun and Camera Through Darkest CLS - Land. Stanford Law Review. V. 36, n. 1, Jan. 1984.

SHAVELL, Steven. Economic Analysis of Accident Law. Cambridge: Harvard University Press, 1987.

SOUZA, Washington Peluso Albino de, Primeiras Linhas de Direito Econômico. 5 ed. São Paulo. Ltr. 2003.

STAMMLER, Rudoph. Economía y Derecho. La concepción Materialista de la Historia: una investigación filosófico social. Madrid: Editorial Réus, 1929.

STIGLER, George J. The Theory of Price. 4 ed. New York: Macmillan Publishing Company, 1987.

TULLOCK, Gordon. The Politics of Bureaucracy. Public Affairs Press. 1965

VENANCIO FILHO, Alberto. A Intervenção do Estado no Domínio Econômico. Rio de Janeiro: Fundação Getúlio Vargas, 1968.

VIDIGAL, Geraldo Camargo. Teoria Geral do Direito Econômico. São Paulo: Revista dos Tribunais, 1977.

WEBER, Max. Economía Y Sociedad: Esbozo de sociología comprensiva. Trad. española de José Medina Echavarría, Juan Roura Parella, Eugenio Ïmaz, Eduardo García Máynez e José Ferrater Mora. México: Fondo de Cultura Económica. 1992.

WILLIAMSON As instituições econômicas do Capitalismo (1989, 2011). 